\title{
Identification of hepatitis $C$ virus subtype $2 c$ by sequencing analysis in patients from Córdoba, Argentina
}

\author{
Viviana Ré, Marta Contigiani, Clara Fumiko Tachibana Yoshida*, Elisabeth Lampe*/+ \\ Instituto de Virologia Dr. J. M. Vanella, Facultad de Ciencias Médicas, Universidad Nacional de Córdoba, Córdoba, Argentina \\ * Laboratório de Hepatites Virais, Instituto Oswaldo Cruz-Fiocruz, Rio de Janeiro, Brasil
}

In Argentina, most information on hepatitis $C$ virus (HCV) genotype distribution comes from studies carried out in Buenos Aires (east province). In order to identify HCV subtypes in central Argentina, nucleotide sequencing of core region was performed in samples from 36 patients living in Córdoba, the second most populated province of Argentina. The sequence analysis identified subtype $2 c$ as the most prevalent (50\%), followed by subtype $1 \mathrm{~b}(33 \%)$ and to a lesser extent by subtypes 1 a (11\%), 3 a (3\%) and $4 a(3 \%)$. This is the first report of circulation of HCV subtype $2 \mathrm{c}$ in this region of Argentina and also such high prevalence has never been found before in the genotype distribution of South America.

Key words: Hepatitis C Virus - Argentina - HCV subtype 2c

Hepatitis $\mathrm{C}$ virus $(\mathrm{HCV})$ is a major worldwide agent for chronic hepatitis. Based on the nucleotide sequence divergence it is classified into six genotypes and many subtypes (Simmonds et al. 1993). The distribution of $\mathrm{HCV}$ genotypes and subtypes are markedly heterogeneous throughout the world, even among nearby geographical regions. The determination of HCV genotypes, subtypes and isolates has been helpful in understanding the evolution and the epidemiology of the virus. Presently, HCV genotyping constitutes the basis for the clinical management of infected patients by providing decisive information about the duration of treatment. Patients infected with $\mathrm{HCV}$ genotypes 1 and 4 are likely to achieve the best rate of sustained remission following a 48-week course of treatment with pegylated interferon and ribavirin, while a 24-week course of therapy appears to be sufficient to achieve the maximal rate of responsiveness in patients infected with HCV genotypes 2 and 3 (Hadziyannis et al. 2004). To perform effective public-health surveillance for new variants, modes of transmission, and further vaccine development efforts, detailed information about sequence variation of subtypes is needed (Simmonds et al. 2005, Weck 2005).

Studies in Argentina from the east province (Buenos Aires region) have demonstrated that genotype 1 (principally $1 \mathrm{~b}$ ) is the most prevalent, followed by genotypes 2 and 3, and in minor extent by 4 and 5 (Oubina et al. 1995, Quarleri et al. 1998, 2000, Picchio et al. 2006). On the other hand, in a study with HCV infected patients resident in Córdoba, the second most populated province of central region of Argentina, we have found an intriguingly high percentage (55\%) of genotype 2 iso-

Financial support: CAPES (Brazil), SeTCIP (Argentina)

${ }^{+}$Corresponding author: elampe@ioc.fiocruz.br

Received 24 April 2007

Accepted 29 November 2007 lates, followed by genotypes 1 (38\%) and 3 (5\%) (Ré et al. 2003), indicating that regional differences of genotype distribution could be present between east and central Argentina. However, no information of HCV subtype distribution in central region of Argentina is available at the present time. The main genotype was determined by restriction fragment length polymorphism analysis of 5'NCR region and polymerase chain reaction (PCR) assay using type specific primers. Although such methods are able to identify correctly the major genotypic groups, only nucleotide sequencing followed by phylogenetic analysis of protein-coding regions, such as core, envelope (E1) or non-structural (NS5) gene of $\mathrm{HCV}$ genome is efficient in discriminating among subtypes, since sequence variation from the $5^{\prime} \mathrm{NCR}$ region does not contain sufficient information to resolve subtypes (Simmonds et al. 1993, Hraber et al. 2006). In the present study, nucleotide sequencing and phylogenetic analysis of core region was performed to provide more accurate determination of $\mathrm{HCV}$ subtypes circulating in central Argentina.

A total of $36 \mathrm{HCV}-\mathrm{RNA}$ positive sera for 5 ' $\mathrm{NCR}$ region by reverse transcription (RT)-nested PCR were sequenced. These samples (16 male, 20 female; mean age 48.2 years-old, range 21-71 years) were from individuals with chronic hepatitis $(\mathrm{n}=26)$, haemophiliacs $(\mathrm{n}=$ $2)$, intravenous drug users $(n=3)$, and blood donors $(n=$ 5). All sera were collected from subjects living in Córdoba, Argentina, and referred to the Institute of Virology, Faculty of Medicine, National University from Córdoba, Argentina. This study was approved by the Ethical Committee of the Universidad Nacional de Córdoba, Argentina.

For sequence analysis, HCV-RNA was extracted from $140 \mu \mathrm{l}$ of serum with QIAamp Viral RNA Mini Kit (Qiagen, Hilden, Germany), reverse transcribed and amplified with conserved primers for core region as described by Viazov et al. (1997). The nested RT-PCR products were purified using the QIAquick Gel Extraction Kit (Qiagen, Valencia, Ca, USA) and submitted to direct nucleotide sequencing reaction in both direction using Thermo Sequenase Cy5 Dye Terminator Kit (Amersham 
Pharmacia Biotech, USA), and analyzed on an automatic sequencer (ALFexpress, Amersham Biosciences, UK). The DNA alignments were generated by the Clustal X program (Thompson et al. 1997). The phylogenetic trees were constructed with the Mega 3 software (Kumar et al. 2004) using Neighbor-joining method and Kimuratwo parameter and their reliability was assessed by bootstrap resampling (1,000 pseudo-replicas). The sequence from nucleotide positions 461 to 711 of the HCV-1 genome (accession number M62321), corresponding to positions 120 to 370 relative to core region, was taken for analysis and classification in genotype and subtypes was performed by phylogenetic analysis together with the main subtype reference sequences obtained from GenBank database. Additional sequences from different countries that shared the same fragment sequenced (251nt) were included in the phylogenetic analysis in order to investigate any possible epidemiological linkage of Argentinean HCV strains with other previously characterized isolates. Corresponding accession numbers and country of origin of strains are given in the figure of the phylogenetic tree.

Results of phylogenetic analysis demonstrated that all strains included in this study cluster accordingly with the appropriate reference sequences. No sequence was identical to any other and no in-frame stop codons, deletions, or insertions were observed in any of the core sequences obtained. From the $36 \mathrm{HCV}$ samples sequenced, $12(33.3 \%)$ were classified as subtype $1 \mathrm{~b}$ and $4(11.1 \%)$ as subtype $1 \mathrm{a}$. All genotype 2 sequences $(\mathrm{n}=$ $18 ; 50.0 \%$ ) grouped inside the clade of subtype $2 \mathrm{c}$ of the phylogenetic tree. One $(2.7 \%)$ sample of genotype 3 was identified as $3 \mathrm{a}$ and one (2.7\%) sample as $4 \mathrm{a}$ (Fig.). Although not statistically significant $(p=0.105)$, the mean age of individuals infected with genotype $2 \mathrm{c}$ was slightly higher (53.4 years) when compared to genotype $1 \mathrm{a} / \mathrm{b}$ (45.6 years). Nucleotide sequence data obtained in this work are available in the DDBJ/EMBL/GenBank databases under the accession numbers AY506666 to AY506695, and DQ374416 to DQ374421.

The phylogenetic analysis of the HCV sequences along with sequences from different countries did not reveal a segregation of the Argentinean sequences with sequences of a particular country. The majority of the sequences were intermingled with strains circulating in other geographical regions. In the genotype $2 \mathrm{c}$ branch of the phylogenetic tree, in which we incorporated previously characterized subtype $2 \mathrm{c}$ strains available in GenBank, we could observe that nine of the Argentinean isolates were interposed with other European strains.

Before the present study, the presence of HCV subtype $2 c$ in Argentina had been detected by sequence analysis in only a few samples in patients from the Buenos Aires region (Quarleri et al. 1998, 2000). Interestingly, one sample of a patient with sporadic chronic HCV infection from the present study (Arg18) grouped with another Argentinean strain isolated in 1998 in Buenos Aires (AF041329). For central Argentina this is the first report of circulation of HCV subtype 2c, which gives more information about molecular epidemiology of $\mathrm{HCV}$ genotype distribution in the country. The HCV

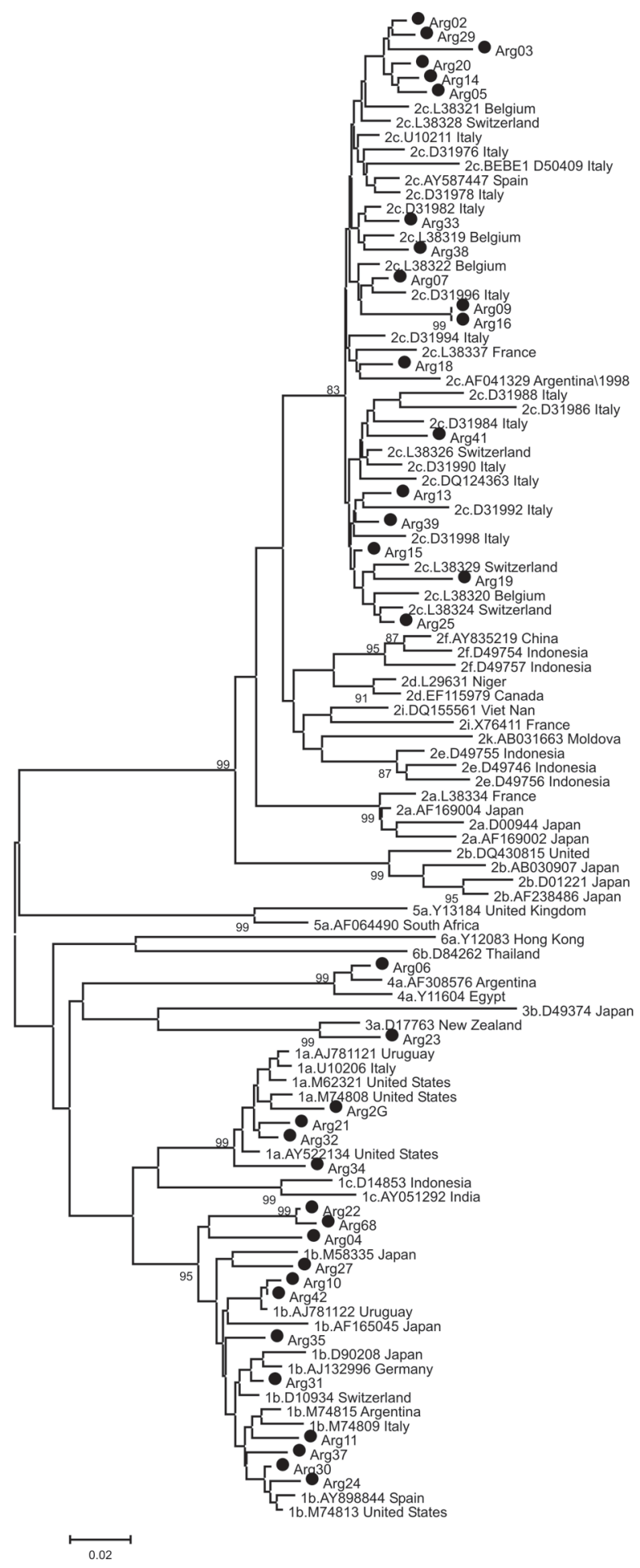

Phylogenetic tree analysis of the core region of HCV genome (251nt) of 36 Argentinean isolates, 17 reference sequences of main HCV subtype and 52 sequences from other country (accession number and country are indicated). Strains belonging to this study are initiated by Arg and marked with a black circle, and the reference sequences used are: 1a-M62321, 1b-M58335, 1c-D14853, 2a-D00944, 2b-D01221, 2c-D50409, 2d-L29631, 2e-D49745, 2f-D49754, 2i-X76411, 2k-AB031663, 3a-D17763, 3b-D49374, 4a-Y11604, 5a-AF064490, 6a-Y12083, 6b-D84262. The bootstrap values $>75 \%$ and genetic distance (bar) are indicated. 
genotype distribution from this study differs substantially from other cohorts of east Argentina as well as in the geographically close region of the South of Brazil, where genotype 1 is predominant (Oubina et al. 1995, Picchio et al. 2006, Quarleri et al. 1998, 2000, da Silva 2007). As far as we know, such high prevalence of subtypes $2 \mathrm{c}$ has not been reported previously in any region of South America.

Nucleotide sequences analysis of the core region allows accurate discrimination of all genotypes and subtypes, showing equivalent phylogenetic grouping as that observed for the NS5 and envelope E1 region of HCV genome (Bukh et al. 1994, Simmonds et al. 1994, Viazov et al. 1997, Simmonds et al. 2005). Cammarota et al. (1995), by performing multiple alignments of different portions of the core region, demonstrated that a segment of 100 nucleotides, positions 160 to 259 , contains typespecific variations sufficient to distinguish subtype $2 \mathrm{c}$ from all other know HCV genotypes and also to construct phylogenetic trees as informative as those obtained with larger core sequences. In this study the positions 120 to 370 relative to core region were taken for analysis and the phylogenetic analysis performed in 36 samples classified $18(50 \%)$ as subtype $2 \mathrm{c}$ by clustering the samples in the branch corresponding to this subtype. Although we cannot exclude the possibility of another subtype of genotype 2 due to the limited number of characterized sequences, the fact that all genotype 2 sequenced strains from this study were classified as $2 \mathrm{c}$ suggests that this subtype might potentially represent an important genotype in the HCV epidemiology of this area of Argentina.

In conclusion, by means of sequence analysis, this study demonstrates that HCV subtype 2c represents an important $\mathrm{HCV}$ genotype in patients living in the centre of Argentina and, most importantly, that this finding has consequential clinical and therapeutic implications in view that infection with genotype 2 is considered an independent predictor factor for sustained response to antiviral therapy (Hadziyannis et al. 2004). Although the relationship between HCV subtypes and the hepatitis severity is still under discussion, a retrospective cohort study performed in Italy with 206 untreated patients chronically infected with genotype $2 \mathrm{c}$ and $1 \mathrm{~b}$ has recently demonstrated that alanine aminotransferase (ALT) flares were significantly associated with genotype $2 \mathrm{c}$ and, consequently genotypes $2 \mathrm{c}$ carriers are at risk of hepatitis reactivation (Rumi et al. 2005). Another study in Japan also shows that genotype $2 \mathrm{c}$ is an important factor for ALT flares (Hiraga et al. 2005).

\section{REFERENCES}

Bukh J, Purcell RH, Miller RH 1994. Sequence analysis of the core gene of 14 hepatitis $\mathrm{C}$ virus genotypes. Proc Natl Acad Sci USA 91: 8239-8243.

Cammarota G, Maggi F, Vatteroni M L, Da Prato L, Barsanti L, Bendinelli M, Pistello M 1995. Partial nucleotide sequencing of six subtype $2 \mathrm{c}$ hepatitis $\mathrm{C}$ viruses detected in Italy. J Clin Microbiol 33: 2781-2784.

da Silva CMD, Costi C, Krug LP, Ramos AB, Grandi T, Gandolfi VL, Menezes ME, Ocampos M, Niel C, Rossetti MLR 2007.
High proportion of hepatitis $C$ virus genotypes 1 and 3 in a large cohort of patients from Southern Brazil. Mem Inst Oswaldo Cruz 102: 867-870.

Hadziyannis SJ, Sette H Jr, Morgan TR, Balan V, Diago M, Marcellin P, Ramadori G, Bodenheimer H Jr, Bernstein D, Rizzetto M, Zeuzem S, Pockros PJ, Lin A, Ackrill AM, PEGASYS International Study Group 2004. Peginterferonalpha2a and ribavirin combination therapy in chronic hepatitis C: a randomized study of treatment duration and ribavirin dose. Ann Intern Med 140: 346-355.

Hraber PT, Fischer W, Bruno WJ, Leitner T, Kuiken C 2006. Comparative analysis of hepatitis $\mathrm{C}$ virus phylogenies from coding and non-coding regions: the 5' untranslated region (UTR) fails to classify subtypes. Virol J 3: 103.

Hiraga N, Suzuki F, Akuta N, Suzuki Y, Sezaki H, Hosaka T, Someya T, Kobayashi M, Saitoh S, Arase Y, Ikeda K, Kobayashi M, Matsuda M, Watabiki S, Satoh J, Kumada H 2005. Clinical and virological characteristics of untreated patients with chronic hepatitis $\mathrm{C}$ who develop serum alanine aminotransferase flare-up. J Med Virol 75: 240-248.

Kumar S, Tamura K, Nei M 2004. MEGA3: Integrated software for molecular evolutionary genetics analysis and sequence alignment. Brief Bioinform 5: 150-163.

Oubiña JR, Quarleri JF, Rudzinski M, Parks C, Badía I, Cappa SMG 1995. Genomic characterization of hepatitis C virus isolates from Argentina. J Med Virol 47: 97-104.

Picchio GR, Bare PC, Descalzi VI, Bussy MV, Soria SM, Raffa MP, Mazzencio NE, Etchehun S, Camera JA, Mosier DE, Villamil FG 2006. High prevalence of infection with a single hepatitis $\mathrm{C}$ virus genotype in a small rural community of Argentina. Liver Int 26: 660-665.

Quarleri JF, Robertson BH, Mathet VL, Feld M, Espínola L, Requijo M P, Mando O, Carallal G, Oubiña J 2000. Genomic and phylogenetic analysis of hepatitis $\mathrm{C}$ virus isolates from argentine patients: a six-year retrospective study. J Clin Microbiol 38: 4560-4568.

Quarleri JF, Robertson BH, Mathet VL, Sinha DS, Badía I, Frider B, Ferro A, Galloppo C, Sookoin S, Castaño G, Oubiña J 1998. Genomic and phylogenetic analysis of hepatitis $C$ virus strains from Argentina. Medicina (B Aires) 58: 153-159.

Ré V, Lampe E, Yoshida CF, Oliveira JM, Lewis-Ximenez L, Spinsanti L, Elbarcha O, Contigiani M 2003. Hepatitis C virus genotypes in Cordoba, Argentina. Unexpected high prevalence of genotype 2. Medicina (B Aires) 63: 205-210.

Rumi MG, De Filippi F, La Vecchia C, Donato MF, Gallus S, Del Ninno E, Colombo M 2005. Hepatitis C reactivation in patients with chronic infection genotypes $1 \mathrm{~b}$ and $2 \mathrm{c}$ : a retrospective cohort of 206 untreatted patients. Gut 54: 402-406.

Simmonds P, Bukh J, Combet C, Deléage G, Enomoto N, Feinstone S, Halfon P, Inchauspé G, Kuiken C, Maertens G, Mizokami M, Murphy DG, Okamoto H, Pawlotsky JM, Penin F, Sablon E, Shin-I T, Stuyver LJ, Thiel HJ, Viazov S, Weiner AJ, Widell A 2005. Consensus proposals for a unified system of nomenclature of hepatitis C virus genotypes. Hepatology 42: 962-973.

Simmonds P, Holmes EC, Cha TA, Chan SW, McOmish F, Irvine B, Beall E, Yap PL, Kolberg J, Urdea MS 1993. Classification of hepatitis $\mathrm{C}$ virus into six major genotypes and a series of subtypes by phylogenetic analysis of the NS-5 region. $J$ Gen Virol 74: 2391-2399.

Simmonds P, Smith DB, McOmish F, Yap PL, Kolberg J, Urdea MS, Holmes EC 1994. Identification of genotypes of hepati- 
tis $\mathrm{C}$ virus by sequence comparisons in the core, E1 and NS5 regions. J Gen Virol 75: 1053-1061.

Thompson JD, Gibson TJ, Plewniak F, Jeanmougin F, Higgins DG 1997. The CLUSTAL X windows interface: flexible strategies for multiple sequence alignment aided by quality analysis tools. Nucleic Acids Res 25: 4876-4882.
Viazov S, Kuzin S, Paladi N, Tchernovetsky M, Isaeva E, Mazhul L, Vasychova F, Widell A, Roggendorf M 1997. Hepatitis C virus genotypes in different regions of the former Soviet Union (Russia, Belarus, Moldova and Uzbekistan). J Med Virol 53: 36-40.

Weck K 2005. Molecular methods of hepatitis C genotyping. Expert Rev Mol Diagn 5: 507-520. 